accommodation. Ocular movements were good. Conjunctivæ were markedly icteroid. The tongue was moist and heavily coated with a yellowish-white pultaceous fur. No tremor, deviation or anomaly of protrusion was present. Pulse was comparatively infrequent, rhythmic, of moderate volume and tension, and the artery was sclerosed. The thorax was emphysematous in type. Expansion was generally diminished, but equal in all directions. Iungs were hyper-resonant throughout. Breath sounds were of weak, vesicular type; expiration was prolonged. A few crepitant râles were audible at both bases. The apex of the heart was visible and palpable in the fifth intercostal space in the midclavicular line; the impulse was feeble. The entire area of cardiac dulness was slightly increased transversely. Soft blowing systolic murmur was audible in the mitral area, was transmitted to the left axilla. It almost replaced the first sound. Pulmonic second sound was considerably accentuated. Examination of the abdomen revealed slight distention. Slight increased resistance and considerable tenderness were present in the right hypochondrium. The liver extended two finger-breadths below the costal margin, its edge being readily palpable. The gall bladder could not be felt. The spleen was slightly enlarged to percussion, but was not palpable.

Course of Disease.-The temperature on admission was 100 F. For the next four days it ranged between 100 and $101 \mathrm{~F}$. It then ascended and for five days ranged between 102 and 104 F. Drfervescence occurred by lysis, the temperature reaching normal on the sixteenth day from the time of admission.

Blood Examination. - On the day of admission the hemoglobin was 5.5 per cent.; erythrocytes, 2,890,000; leucocytes, 8,200 ; differential count, polymorphonuclear, 60 per cent.; small lymphocytes, 8 per cent.; large lymphocytes, 32 per cent. Three marked positive Widal reactions were obtained.

Feces.-Typhoid bacilli were isolated in considerable number.

Urinalysis. - On day of admission the urinary findings were as follows: Color, dark amber; reaction, acid; specific gravity, 1.023 ; slight trace of bile; no albumin or sugar. Microscopic examination disclosed triple phosphate, uric acid, epithelial cells, bacteria and débris.

On admission this case presented the evidences of an ordinary catarrhal cholecystitis and cholangitis. The positive Widal reaction, the absence of a leucocytosis, the marked increase in the large lymphocytes and the presence of the typhoid bacilli in the feces, led to a diagnostic infection of the gall bladder and ducts with the Eberth's bacillus. As is well known, cholecystitis and cholangitis are rather frequent as complications or sequelæ of enteric fever.

Primary typhoid cholecrstitis and cholangitis-that is, inflammation of the biliary tract, without other evidence of past or present typhoid infection-are comparatively rare. In reviewing the literature on the subject I find that Pratt ${ }^{1}$ was the first to call especial attention to this condition. He reported two cases, one of which was gangrenous and associated with a localized peritonitis. Similar cases have been reported by Cushing, ${ }^{2}$ Richardson, ${ }^{3}$ Mitchell, ${ }^{4}$ Stockton and Lyte, ${ }^{5}$ Burley, ${ }^{6}$ Stewart, ${ }^{7}$ and Kelly. ${ }^{8}$ The preceding case well iliustrates the necessity of making careful examination of the blood and feces, for if this is not done, the essential underlying etiological factor will remain unrecognized.

I am confident that these cases occur far more frequently than the literature on the subject would lead us to believe. Careful examination of the blood and

1. Am. Jour. Med. Sc., November, 1901.

2. Johns Hopkins Hosp. Bull., 1898, ix, 91

3. Boston Med. and Surg. Jour., Dec. 2, 1897.

4. Maryland Med. Jour., 1901, xliv, 13.

5. New York State Jour. Med., 1902, 1i, 232.

6. Am. Med., October, 1903

7. Am. Med., 1904, vii, 1019

8. Am. Jour. Med. Sc., September, 1906. feces not being made in all cases, the origin of the disease is attributed to other factors than the typhoid bacillus.

\section{ANGIONEUROTIC EDEMA OF THE GENITALS.}

HARRY I. WIEL, M.D.

Assistant in Medicine, Cooper Medical College. SAN FRANCISCO.

Angioneurotic edema is a condition interesting enough to warrant the reporting of cases, and this patient presents clinical aspects rather striking and probably without the common experience of most of us. To transcribe his clinical history in full would be to write a monograph-even to relate essentials details is no easy task, but the following outline contains the salient features.

History.-Mr. X., age 27, single. Family history unimportant, except that both his aged parents suffer with chronic organic cardiac disease. A young man in good circumstances, he has been in the front rank in athletics, and has indulged in the usual life of young men of the day, but not to any great excess. No serious diseases, other than repeated attacks of gonorrhea, until three years ago.

Three years ago, while in New York, the patient called me to see him. He had been under treatment by a physician for a chronic gonorrhea, but at this time he was feeling very miserable, suffering particularly with nocturnal fever and joint pains, commencing about 4 o'clock every afternoon. A look at him disclosed a typical macular syphilide over his trunk. As he had been under the physician's regular observation for his gonorrhea, it was all the more remarkable that there had been no sign nor history of primary lesion. (The patient since informed me that while under treatment for the gonorrhea the physician was accustomed to take the sounds directly from the instrument cabinet to the urethra without sterilizing hands, penis, urethra or sounds. Thus the possibility of intraurethral chancre could not be excluded, in fact was made very reasonable.) I concurred in the diagnosis of syphilis.

Treatment.-The patient's course since then has been devious. Rigorous anti-Iuetic treatment was instituted and carried out. He returned to his home in San Francisco in a few months, and went under the care of Dr. H. B. Reynolds.

Subsequent History.-One year later I was with the patient at Lake Tahoe, whither he had gone to rest from rigorous mercurial treatment and to seek climatic relief from the intense headaches. with which he had become afflicted. While occupying a seat one day he became suddenly completely paraphasic, and on attempting to walk had a staggering gait. He was removed to San Francisco at once, and there in consultation with Drs. Herbert Moffitt, E. C. Sewell and H. B. Reynolds, it was agreed after extended and thorough examination that he probably had a luetic meningitis, though the sudden onset spoke for intracranial arterial disease. (The symptoms completely disappeared before the patient's arrival in San Francisco, an interval of twenty-four hours.)

For one year following, the patient was bed-ridden in a hospital for what was actually a profound psychasthenia with many hysterical features. He was obsessed with phobias, was neurotic in the extreme, and insisted on having an attendant constantly with him. His physical symptoms were protean, headaches, nausea, diarrheas of violent nature, universal pains, in fact the whole gamut of possibilities.

At the end of the year I returned to San Francisco and found him just about on his feet again. (This was two years ago.) In a few months he was approximately a normal individual, physically and mentally, was back at his tennis and planning to finish his law course at Columbia University.

Six months ago I was called to se the patient. He had a violent diarrhea, a very high temperature (103.5) and a dicrotic pulse; no enlarged spleen nor rose spots. After three days in bed with high fever he became well over night, the temperature falling by crisis. 
Prescnt Illness.-Four months ago the patient called me at 3 a. $\mathrm{m}$. While indulging in sexual intercourse a few hours previously he suddenly felt as though some insect with a sharp mandible had bitten him on the left side of his scrotum. On arriving home he found the skin of that side of the scrotum quite res! ; he put on at once Pond's extract and camphor, but the itehing became intense and large bulla formed. I saw him in a fow lonurs and diagnosed a dermatitis from the irritants applied. The skin of the left side of the scrotum was swollen and red and bore large vesicles containing seropurulent fhuid. Under or in spite of treatment the condition subsided in about a week, and I was extremely puzzled as to what the initial trouble had been.

A fow weeks later, while lying in bed, he experienced the identical sensation in the scrotum and foreskin and sent for me. I found the entire scrotum and foreskin enlarged to elcphntine size, red, edematous, but no lesions of any kind, Fightful itching was prescnt. Antipruritics and purges were civen, and the condition subsided in a day. The testicles themelves could be made out and were normal.

since then the patient has had three attacks, all similar in their feature to the second attack, i. e., with no vesicular formation. Parasitic disease was excluded, and it was palpable in the attacks following the first that we were dealing with an angioneurotic edema.

A suggestive feature in the case is that shortly before the onset of these attacks, the patient had gone through a typhoid-like seizure of short duration and subsiding suilienly. Could not this case in its latter features belong to that growing field of clinical entity, the erythemas and purpuras with visceral crises? If so, what relation, if any, has it to the luetic infection, or better still, did he ever have lues?

To settle these questions would require a more detailed history, for abundant as the above data are, they represont but a small portion of those at hand. The angioneurotic edema is the main reason for the publication of the case. Its general clinical aspects, however, assume a remarkable interest for those in touch with the prtient.

943 Van Ness Ave.

\section{CASE OF LEFT SCROTAI IIERNIA CONTAIN- ING THE CECUM AND APPENDIX.}

\section{J. CLARKF JOGAN, M.D.} PITTSBURG.

The following case is reported because of the commative rarity of the anatomic findings, beyond which it prosented no points of special interest.

History.-Patient, aged 3 years, a twin and a 7 months child. The parents informed me that the hernia was present at birth, but it is fairly reasonable to suppose that it may have appeared soon after birth. They also stated that the hernia varied in size, but never disappeared entirely. The child was well nourished and apparently normal, except that it had never walked, and in the recumbent position had develoned eversion of both legs to practically 90 degrees.

Examination.-The left side of the scrotum was filled with a mass the size of a lemon, a part of which was easily reduced, with audible signs of gas. I was not, however, able to accomplish complete reduction, either at that time or later, under anesthesia, and as the remaining mass felt doughy, I diagnosed a hernia of the small bowel and omentum.

Operation.-On opening the sac the small bowel, which was thought to be the ileum, was found uppermost. On attempting to draw this up from the bottom of the scrotum, some resistance was encountered, but after a little perseverance the adhesions gave way, and the entice cecum and appendix presented, and the underlying loop of gut proved to be part of the ascending colon. The cecum was thick and friable, and tore on attempted reduction, which was very difficult, necessitating-one suture. The cecum and appendix were very much congested. The appendix measured $7 \mathrm{~cm}$. in length and $8 \mathrm{~mm}$. in diameter after three days' hardening in alcohol.

Owing to the length of time taken by the appendectomy, and the reduction of the thick-walled, friable cecum, it was not deemed wise to subject the child to farther examination at the time, and the herniotomy was completed in the usual manner. Subsequent examinations, however, revealed nothing abnormal and the child made an uninterrupted recovery.

\section{FOREIGN BODY REMOVED FROM RIGHT BRONCHUS BY LOW TRACHEOSCOPY.}

\section{RICHARD H. JOHNSTON, M.D. BALTIMORE.}

History.-March 6, I was hastily called to see Mary P., aged 10 years, who for some time had suffered from laryngeal dyspnea, which had gradually increased in severity until radical measures were necessary. She was taken to a laryngologist who promptly made a diagnosis and inserted a No. 3 hard rubber tracheotomy tube into the trachea to give better breathing space. He dilated the stenosis successfully so that the patient was much improved.

At 2 o'clock in the afternoon March 6 the tube was removed, eleaned and replaced. Two hours later, while eating cake, she had a sudden attack of coughing and cyanosis which passed off in a few moments. A little later, the attack was repeated. The nurse, much alarmed, immediately summoned a physician, who attempted to remove the tube. He succeeded in getting only the outside plate; the tube was missing. In the absence of the attending laryngologist $I$ was asked to see the patient.

Examination.-She was lying on her back, breathing with some difficulty and coughing incessantly. Finding her in no immediate danger, I turned my attention to the plate, and found that in some way the tube had become unscrewed until it was almost off the plate. During the acts of swallowing the cake it had evidently dropped into the trachea, giving rise to the sudden cough and cyanosis. Immediate operation for the removal of the tube was advised.

opcration.-The patient was chloroformed, with the mask over the nose and mouth, and the tracheotomy wound was cleaned and enlarged for half an inch. Jackson's $5 \mathrm{~mm}$. tracheoscope was passed through the tracheal wound, the mucous membrane touched with cocain and adrenalin, blood and secretion wiped away and careful search made for the missing tube. After we had reached almost to the bifurcation, the dark edge of the foreign body could be seen. The tube had worked its way down into the right bronchus while the upper end was in the trachea close to the bifurcation. With each pulsation of the heart the dark edge moved from side to side. Forceps were introduced through the tracheoscope, the edge of the tube was seized, and tube and forceps were pulled out together through the tracheal wound. The entire operation lasted about fifteen minutes. The patient was nauseated the next day, but with this exception recovery was uneventful. There was not the slightest rise of temperature.

919 North Charles Street.

Staining of the Negri Bodies.-L. Frothingham, in the American Journal of Public Hygiene, states that the stain should be made freshly every day, as the Negri bodies fail to take up the red readily after the solution is from six to eight hours old. The Negri bodies stain from a pale pink to a purplish red, and often contain numerous minute dark blue dots. The cells stain more or less blue, the red blood corpuscles not at all or are yellowish in color, rarely pinkish. He calls attention to the fact that not infrequently the Negri bodies in the Purkinje cells stain a very pale pink, while those in impres. sions of the cornu Ammonis, made on the same slide and stained at the same time, are deeply stained. He has observed this same peculiarity in the sections. 